be used as a reference book and does not provide as good value for money as the other books; the remaining three books all have good points - Burns, for example, emphasizes human genetics throughout, Avers integrates the genetics of discontinuous and continuous phenotypic variation, and an important point in favour of Wagner et al. is that I have already received favourable reports of it from my own students. However, I am disinclined to recommend any of the books except Ayala and Kiger, and Fristrom and Spieth, except perhaps for reference in libraries.

\title{
Microbial genetics abbreviated
}

\section{J.R.S. Fincham}

Genetics of Microbes. By Brian W. Bainbridge. Pp.193. (Blackie/Halsted: 1980.) Hbk £16.95; pbk £7.95, \$27.95.

THIS book deals with fungi as well as with bacteria and bacteriophage, and attempts to take the reader from the fundamentals up to the frontiers of research. It covers a reasonably comprehensive range of topics - some old, such as parasexual reproduction in fungi, and others rather new, including mitochondrial genetics of yeast, genetic analysis in streptomycetes, and in vitro manipulation and cloning of DNA in plasmid and phage vectors. The basic systems of gene exchange in bacteria, including transposons, are all described, albeit sketchily in some cases. Lambda phage gets considerable attention.

To cover all this in 170 pages (exclusive of bibliography), as Dr Bainbridge has attempted to do, is an ambitious undertaking, and I cannot say that he has been wholly successful. Conciseness is too often the enemy of clarity. Much information is presented in the form of complex diagrams, often based upon recent reviews and in themselves good and well chosen. But the captions are usually very short and often supported by only a telegraphic sentence or two in the text. Sometimes essential explanations or even facts are omitted in the rush to get on to the next topic. For example, after a brief account of gene conversion we come, a few pages later, to evidence from random meiotic

\section{Genes and behaviour}

\section{B. Burnet}

Behavioral Genetics: A Primer. By R. Plomin, J. C. DeFries and G. E. McClearn. Pp.417. (W. H. Freeman: 1980.) Hbk $£ 14.80, \$ 24.95$; pbk £8.10, \$14.95.

BEHAVIOURAL genetics is the discipline linking the biological and behavioural sciences. It is concerned with the systematic study of the heritable bases of behaviour and the role of behaviour in evolution. The problem with teaching it is that intelligent discussion of the interesting issues depends upon a background knowledge of genetics, behaviour, statistics and evolution, and this is what the book provides. Following products which is interpreted as favouring the idea of negative crossover interference. No hint is given that, in the light of tetrad analysis, data of this kind can be largely explained in terms of gene conversion. In the same chapter, an otherwise clear account of the Poisson distribution and its application to recombination theory is spoiled by a paragraph implying that a mean chiasma frequency of 0.5 corresponds to 50 per cent recombination (a factor of two missed here). In the chapter on the analysis of the yeast mitochondrial genome, the uninformed reader is not told that mitochondrial recombination is customarily detected and assayed in diploid hybrid clones and he will probably come away with the impression that it happens only in meiosis.

This, then, is not the ideal book, but it has its good points. The account of genetic engineering will be useful for beginners and the discussion of Streptomyces genetics provides information not readily available elsewhere except in the specialist literature. The chapter on DNA repair and mutation gives an accurate up-to-date account, albeit virtually confined to effects of UV. Several of the tables and figures provide good summaries of things one of ten wants to look up, and the bibliography is a useful guide to the primary sources.

J.R.S. Fincham is Buchanan Professor in the Department of Genetics, University of Edinburgh.

some historical background about Darwin and Galton, the authors discuss the theory of evolution in relation to behavioural genetics and sociobiology. There is a clear and concise introduction to genes and chromosomes and to the quantitative and population genetic approaches to the study of behaviour. Especially valuable is the careful explanation of how genetic variation in human behaviour is studied and how this yields information about the environmentality as well as the heritability of behavioural differences. They draw together the results of recent surveys which indicate that IQ differences are less heritable than earlier studies have suggested.

The authors take their material mostly from studies on human beings and small mammals except in their chapter "Mechanisms of Heredity and Behaviour', which includes bacteria, protozoa, round worms and insects. Those who, like myself, believe that invertebrates will for some time provide the arena for testing rival theories about the causal networks linking genes and behaviour may feel that advances using fruitflies and nematodes deserve more emphasis. The assertion on p.41 that "amphibians arose from the invertebrate lobe-finned fish" may discomfort vertebrate palaeontologists, and I note with interest a novel enzyme in Fig.10.1.

This is an excellent text, not only for the quality of the scientific explanations but because it deals critically with several controversial issues. It shows why behavioural genetics is intellectually exciting and practically relevant to the human situation. I recommend it for course work in the biological and behavioural sciences, and to the general scientific reader.

B. Burnet is Reader in Animal Genetics at the University of Sheffield.

\section{"Mini Luria"}

\section{H. Watson}

Introduction to Modern Virology, 2nd Edn. By S.B. Primrose and N.J. Dimmock. Pp.251. (Blackwell Scientific/ Halsted: 1980.) Pbk £7.50, \$19.95.

IN this second edition of Introduction to Modern Virology, forming part of the Blackwell Basic Microbiology series, Dr S.B. Primrose has been joined by his colleague Dr N. J. Dimmock. The 251-page volume is amazingly comprehensive, forming a "mini Luria" in that it adopts the same general plan of Luria's General Virology (Wiley, 3rd Edn 1978). The treatment follows that given in a number of universities offering comprehensive virology courses as a component of undergraduate microbiology degrees.

An introductory chapter gives an historical survey of the development of ideas on the nature of viruses; a useful guide on basic techniques of animal virology is appended. Chapters on structure and nucleic acids of viruses are followed by six core chapters on the virus growth-cycle. Later chapters deal with such topics as virus pathogenicity, the immune system and interferon, vaccines and chemotherapy, and tumour viruses. A useful addition is a concluding chapter surveying virus families giving their "official" names, although the authors appear to be unaware of the recent U-turn 